\title{
A Preliminary Assessment of the Hydrocarbon Potential of Kerio Valley Basin: Gravity and Magnetic Interpretation
}

\author{
Abiud Masinde ${ }^{1}$, Cleophas Simiyu ${ }^{1}$, Innocent Murunga ${ }^{1}$, George Muia ${ }^{1}$, Aaron \\ Waswa $^{2}$, Justus Barongo ${ }^{2}$ \\ ${ }^{l}$ (National oil Corporation of Kenya, Kenya) \\ ${ }^{2}$ (Geology, University of Nairobi, Kenya)
}

\begin{abstract}
The aim of the study was to assess the hydrocarbon prospectivity of the Kerio Basin in the Kenya Rift. Regional gravity and magnetic data sourced from the International Gravity Bureau (BGI) and Earth Magnetic Anomaly grid (EMAG2) respectively, were processed and analysed for major structures and geological anomalies based on variations in density magnetism and or chemistry of the rocks. Gravity Isostacy data shows low gravity anomalies of up to -100mGals that depict a deeper basement prominent to the southern part of the study area. Gravity profiles show that sediment thickness gradually increases to the south where we expect hydrocarbon accumulation. The magnetic anomaly map reveals low susceptibility rocks of between $20 n T$ to -200nT to the south of the basin. Magnetic tilt depth indicates sediment thickness of 2-3.5Km above the basement. The results agree with the observed gravity values of -100mGals to -200mGals in the same area. Hence the southern part of the study area shows the highest potential for hydrocarbon accumulation. Integration of these data with seismic and other geophysical methods in the southern area of the Kerio Basin can help gauge the hydrocarbon potential and reduce the uncertainty in the preliminary results.
\end{abstract}

Keywords: Analytic signal, Gravity Isostacy, Hydrocarbon prospectivity, Kerio basin, tilt depths

\section{Introduction}

The study area, located within Kenyan Tertiary rift between latitudes $0^{\circ} 0^{\prime} 0^{\prime \prime} \mathrm{N}-1^{\circ} 15^{\prime} 0$ " $\mathrm{N}$ and longitudes $35^{\circ} 25^{\prime} 0^{\prime \prime} \mathrm{E}-36^{\circ} 25^{\circ} 0^{\prime \prime E}$, lies between the Cheranganyi hills to the West and the Tugen Hills to the East (Fig 1) occupying roughly $6,530 \mathrm{sq} \mathrm{Km}$ in area. Kerio valley in block $12 \mathrm{~A}$ is jointly operated by Tullow oil, Delonex and Africa Oil [1,2]. Gravity data are analysed to determine the dominant anomaly trends, describe structures constraining sedimentation, map basement depths and recommend possible prospects. To avoid often ambiguity of gravity interpretation, magnetic and other geophysical data are integrated to constrain the interpretation [3]. The gravity data consisting of Isotactic, Free-air and Bouguer anomaly grids were obtained from the International Gravity Bureau (BGI) [4].

The EGM2008 model includes surface gravity measurements from land and satellite gravity with a 1'X1' grid resolution [5]. Magnetic data were derived from the Global Earth Magnetic Anomaly grid (EMAG2). Satellite, ship and airborne magnetic measurements were compiled to generate the EMAG2 grid with a resolution of 2 arc min and an altitude of $4 \mathrm{~km}$ above geoid [6].

\section{Relationship to Previous Geophysical Studies}

Exploration interests in the basin were sparked by the discovery of substantial oil reserves in the Ngamia and Amosing wells of the Lokichar basin by Tullow Oil in 2012 [7]. In 2013, Tullow Oil conducted a Full Tensor Gradiometery survey followed by a 674Km 2D seismic survey completed in early 2014 [8]. Prior to that, Mariita and Keller [9] associated gravity highs observed along the rift axis to mafic bodies related to volcanics. Many geophysical investigations undertaken over the last decade within the Kenyan Tertiary rift as summarised by [10-15] depict a dominant low gravity within the rift. The regional seismic and gravity studies based on the results of the KRISP project was focused on the northern and southern Kenyan rift [9]. However, little has been done to explore the Kerio valley basin with standard precision.We use an integrated geophysical approach to narrow down the results of [10] to the Kerio valley basin. Seismic data acquired by National oil Corporation of Kenya (NOCK) in 1990 is interpreted by [16] to show large boundary fault, the Elgeyo Fault that marks the boundary to the west. 


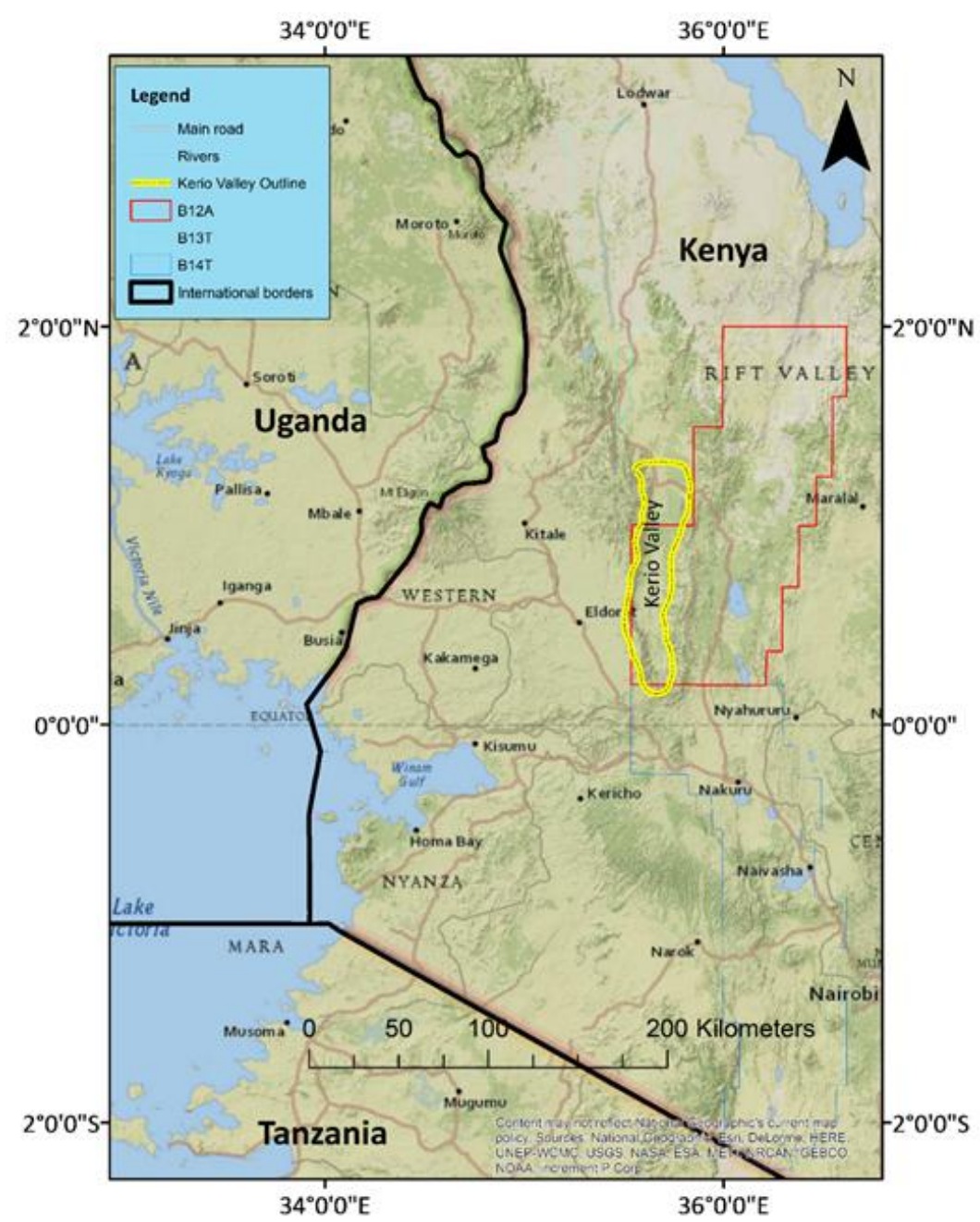

Figure 1: Location map of the Kerio basin

\section{Tectonic and Geological Setting}

The Kenya Rift around latitude $1^{\circ} \mathrm{N}$ is structurally complex with unique features comprising strings of $\mathrm{N}-\mathrm{S}$ oriented half-grabens of the Palaeogene-Miocene age. The $1500 \mathrm{~m}$ high Elgeyo Escarpment is a major border fault that defines the western edge of the rift [17]. Two sub basins lie between the rift borders: the Baringograben and the Kerio basin. Lakes Baringo and Bogoria lie in the Quaternary trough forming the main present depocentre in the region. To the west of Lake Baringo is the uplifted Tugen Hills fault block. Most of the Neogene succession of volcanic and sedimentary rocks is exposed in the Tugen hills. The dip slope west of the hills' crest descends toward Elgeyo and is buried under young sediments of Kerio valley [18]. The geologic history of the Kerio-Baringo region consists of dynamic landscapes related to tectonics, environmental changes, and volcanic activity.

The region around Kerio forms part of the Cenozoic ( $65 \mathrm{Ma})$ rifted zone of the northern Kenya rift. It comprises roughly of the N-S striking rift features oblique to the original NW-SE rift basins that developed during the Cretaceous-Palaeogene times [19]. [18] asserts that the Kerio Basin underwent at least two main rifting phases. The early phase during the Palaeogene that resulted in a full graben underlies the N-S axis of the Kerio valley. The Kerio basin comprises of young strata and Tertiary sediments of $6-8 \mathrm{~km}$ thick that overlie the Proterozoic basement.

Ultimately, the basins of NW Kenya contain a detailed record of tectonic evolution and rift valley geology in their sedimentary structure. It is envisaged that before modern basins came into being, there were Palaeogene lakes, Cretaceous fluvial systems, and Miocene volcano-sedimentary sequences that left a regional fossil record [20]. The current basins originated in the Pliocene tectonic movements of rifting and subsidence that created depocentres for Pleistocene sediments. The extension mechanisms happened during the Palaeogene times, simultaneously with rifting in northern Kenya and neighbouring regions [21, 22]. [23] indicate that the 
above events instigated the formation of N-S trending sub basins of the Central Kenya Rift, Baringo basin to the east and Kerio basin to the west. Exposures of fluvial and lacustrine sediments of the Palaeogene age include green laminated sandstone and shale of the Kamego and Kimwarer formations in the Baringo and Kerio basin respectively [24]. The two major formations symbolize the upper segment of the 6-8km thick sediment [18]. The exposures are found at the base of the Tugen Hills that comprises sediment sequences of the Neogene System. Phonolitic and basalitic volcanic relatively capped the Baringo and Kerio basins in the period 23-10Ma contemporaneous with fluviolacustrine sedimentation resulting in the Tambach and Ngorora Formations during the second phase of rift tectonics $[24,25]$. Several hundred meters of these sediments outcrop extensively in the Tugen Hills between Baringo and Kerio basins [23].

\section{Data Processing Method}

Gravity and magnetic methods are based on [26]. An Isostatically corrected map (Fig 2) which is produced by subtracting long wavelength anomalies of deep masses within the crust or mantle was preferred to a Bouguer anomaly grid because it reveals more clearly about the density distributions within the upper crust where most geologic and tectonic researchers are interested [27]. The grid is initially filtered using a Hanning low pass filter of order 2 to remove low wavelengths. Four profiles were extracted from the grid to give a 1D interpretation along straight lines (Fig 2). Magnetic grid was corrected for IGRF, diurnal, filtered using a $1 \mathrm{~Hz}$ low pass $10 \mathrm{~km}$ Hanning filter to reduce noise, later, reduced to equator to place all anomalies directly over underlying sources and make anomalies less complicated. Tilt derivative of the magnetic grid was used to estimate depth to basement [26, 28]. This was done by measuring the widths of the tilt ridges which are relatively parallel, symmetric and uniform. These widths are halved to estimate depths are to various targets and generate a depth contour map [29]. The depth map represents elevations with respect to the mean sea level. Magnetic Tilt angle has the advantage of enhancing weak signatures due to the AGC obtained by the arctan function that restricts the Tilt angle to within the range $-90^{\circ}$ to $+90^{\circ}$ irrespective of their amplitude or wavelength [30]. The residual analytic signal anomaly map is used to capture the response of existing magnetic signatures even the reversely magnetised ones [31]. Analytic signal is computed from the magnetic map as a square root of sum of squares of all gradient fields [26].

\section{Data Interpretation}

The Isostatically corrected gravity anomaly indicates N-S oriented basin with highs on both sides (Fig 2). The gravity anomaly variation in the study area is about $95 \mathrm{mGals}$. 


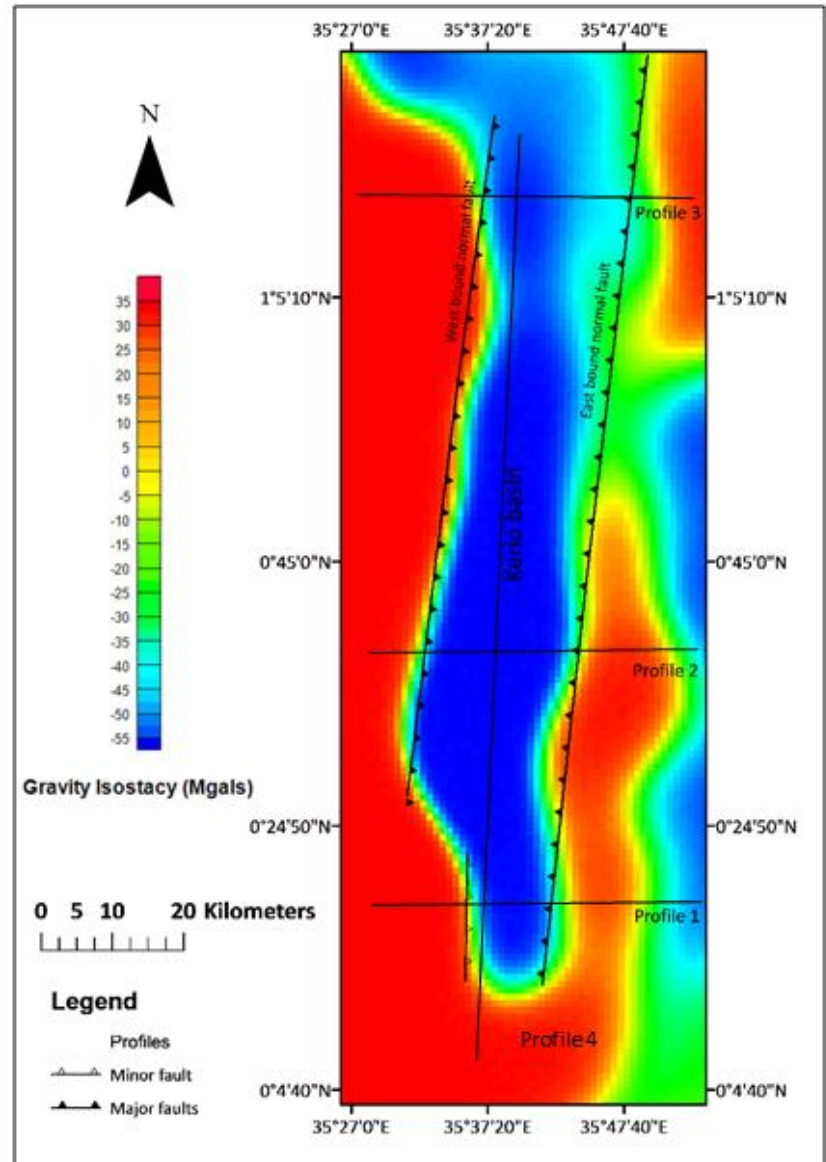

Figure 2: Isostatically corrected gravity map

Tectonic units of Elgeyo Escarpment high and Tugen hills uplift show prominent gravity highs of about $40 \mathrm{mGals}$ depicting presence high density signatures probably granitic or mafic intrusions. Kerio basin is characterised by low gravity anomalies ranging between $35 \mathrm{mGals}$ to $-55 \mathrm{mGals}$ related to variations in quantities of sediments deposited. Light colours in the northern end shows low sediment deposits while deep colours to the south depict deeper sediments. Although there is little sediment variation in the middle section of the basin, Kerio basin probably deepens towards the west, this is shown by the overall unclosed east-extending low gravity anomaly. Kerio basin exhibit fault bounded Sedimentation. The two major normal faults on either side of the basin play a major role in constraining sediments (Fig 2). The west bound fault (Elgeyo border fault) is a basement fault associated with the major rift throwing to the east and probably influencing the N-S orientation of the east bound fault which throws west.

The three east-west oriented profiles extracted from gravity reveals a general low trend at the centre and high trends on the sides (Fig 3). Profile 1 south of the basin indicates a gravity variation of 50mGals$150 \mathrm{mGals}$. 

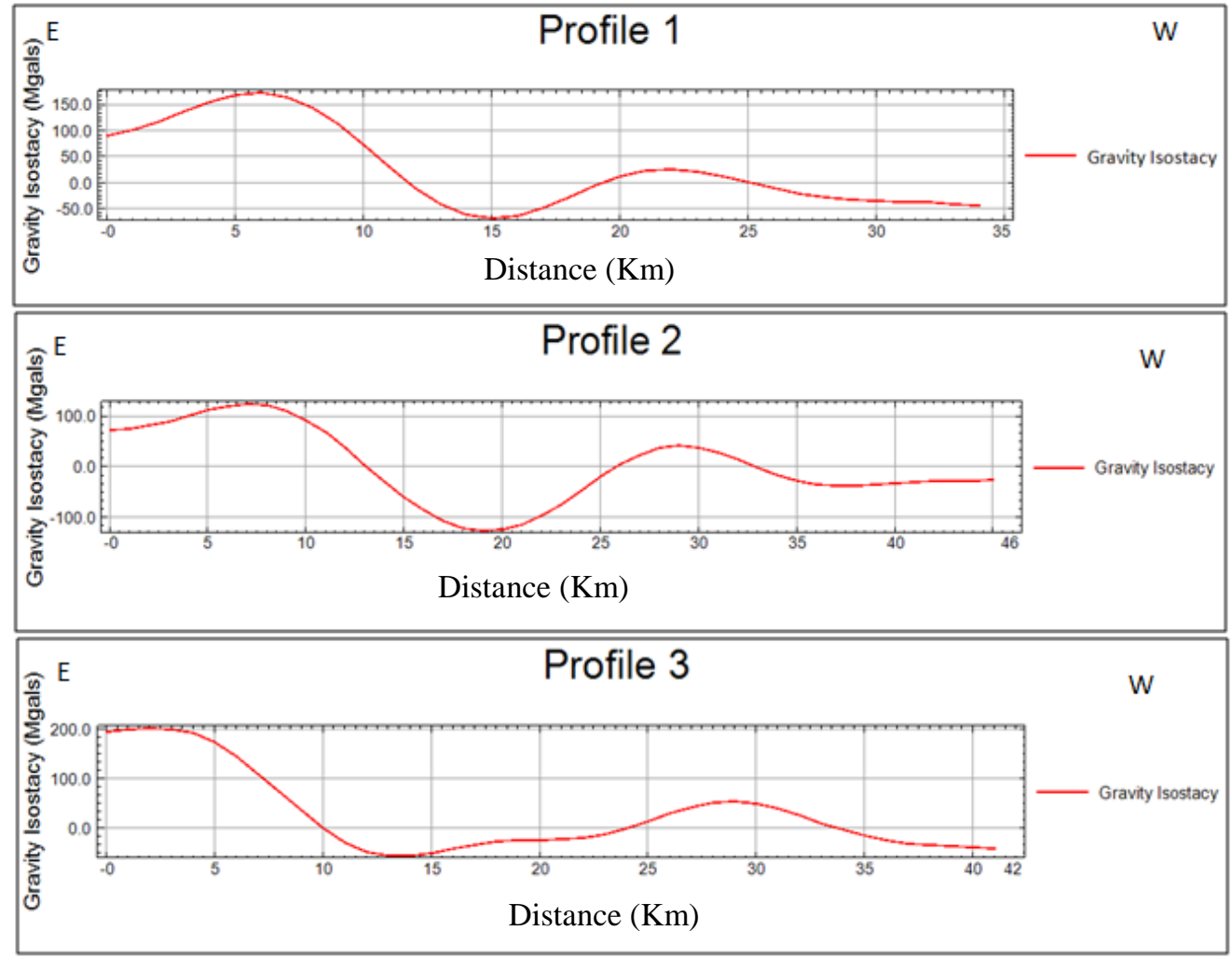

Figure 3: East-west gravity profiles

About $5 \mathrm{~km}$ in breath of middle section of the basin is covered by low gravity deep sediments up to 50mGals. Notably, the low gravity sediments continue east of the basin, this is probably attributed to the continuation of the Kerio basin into Baringo basin which is east of the study location. Profile two depicts a bow shaped basement shown by low gravity sedimentation of about $-120 \mathrm{mGals}$. More than $10 \mathrm{~km}$ in width of the basin is covered by low gravity sediments of about $-100 \mathrm{mGals}$. This is the location of the largest depocentre and with the deepest section of the basin.

The volcanic Elgeyo escarpment and Tugen hills are mapped by the high gravity profiles on either sides of the basin. Profile 3 shows a gravity variation of $200 \mathrm{mGals}-50 \mathrm{mGals}$. The western arm of the profile has the highest gravity values attributed to the location of the volcanics of the Elgeyo escarpment high. Contrary to profile 2 which delineates the high gravity Tugen hills east of the basin, profile 3 suggests a continuation of low gravity east of the study area which compliments profile 1 trend (Fig 3). Kerio basin is separated from the Baringo basin by the Kamasia horst [9].

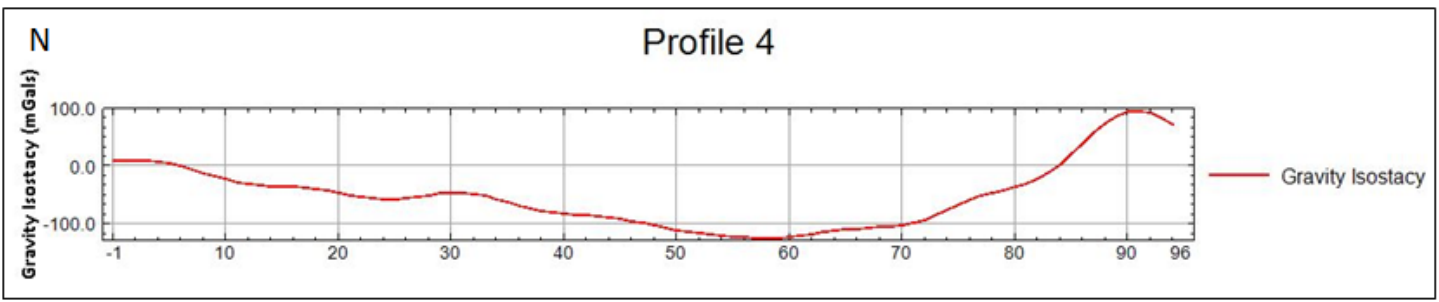

Figure 4: North-south oriented gravity profile 
Profile 4 is a N-S cross-section through the middle of Kerio Basin that reveals sediment thickness increases southwards based on the lowest gravity anomaly of over -100mGals (Fig 4). This is in line with the gravity map that shows lower anomalies towards the south.

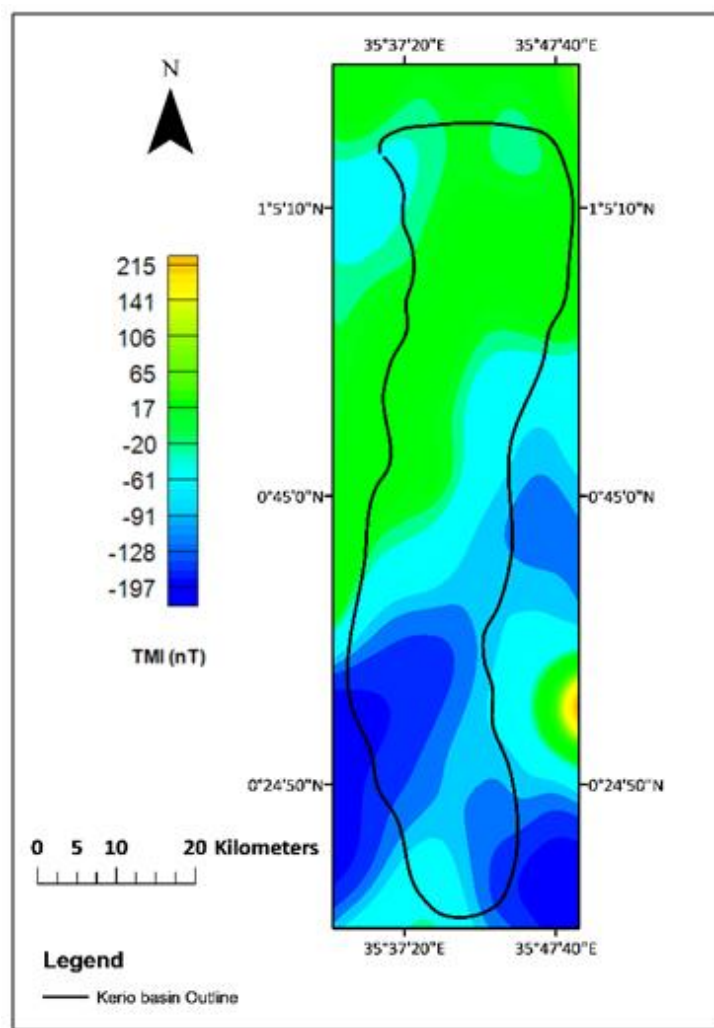

Figure 5 (a): Magnetic anomaly map

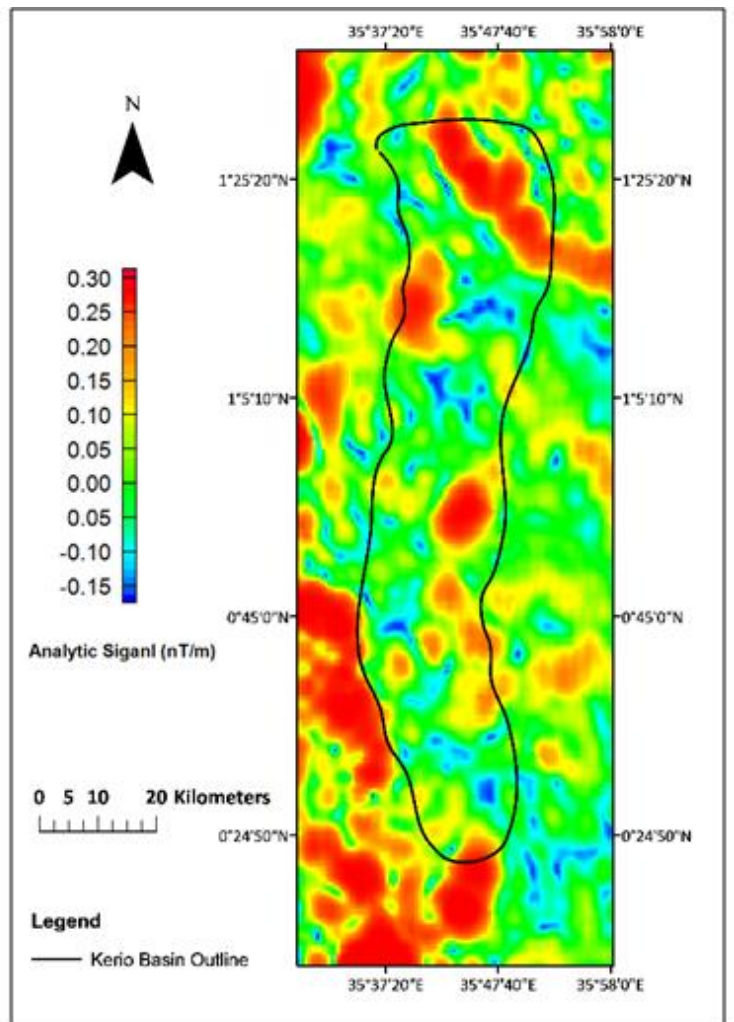

Figure 5 (b): Analytic signal anomaly map

Magnetic anomaly map reveals low susceptibility rocks south-west (Fig 5 (a)) and high magnetic rocksnorth of the basin a similar trend to gravity interpretation. This is probably the largest depocentre filled with sediments whose susceptibility ranges between $-20 \mathrm{nT}$ to about $-197 \mathrm{nT}$. Gravity map of the same location reveals low values up to $-55 \mathrm{mGals}$ (Fig 2). Low magnetic rocks ranging between -20 to about $-91 \mathrm{nT}$ are also observed north of the basin corresponding to a possible location of a northern sub-basin (Fig 5 (a)). The same is observed on gravity data with gravity values of $-15 \mathrm{mGals}-50 \mathrm{mGals}$ (Fig 2). Low magnetic signatures extends east of the Kerio basin to Baringo basin. The magnetic highs on the northern and south- eastern sections relate to the highly susceptible volcanic rocks of the Elgeyo escarpment and Tugen hills consecutively. [32] describes Kerio basin as a quiescent half graben suspected to be filled with fluvial, lacustrine sediments and thick piles of volcanics. The analytical signal anomaly map (Fig 5 (b)) confirms the presence of basaltic signatures overlaid on sediments. They are identified as the high amplitudesignatures on the near surface. The northern section is dominated by these basalts compared to the southern section (Fig 5 (b)). This is likely to be great challenge to seismic acquisition projects in the basin and probably most of the Tertiary rift due to high signal attenuation.

\section{Depth estimation and Lineament analysis}

Although magnetic data is not good for mapping structures close to the magnetic equator, the data is still good to map depth to basement [26]. The tilt anomaly map (not shown) is used to highlight lineament anomaly, amplitude variation contrasts in density of causative bodies and depth estimation[33]. The map suggests anomalies prominent NE with long wavelength signatures. The NW and SW sections depicts linear structures with both long and short wavelengths. Shorter wavelength signatures are dominant for the $\mathrm{N}$ to NE oriented linear structures. Tilt depth predicts deep basement at 3 to $3.5 \mathrm{Km}$ bellow mean sea level (Fig 6). 


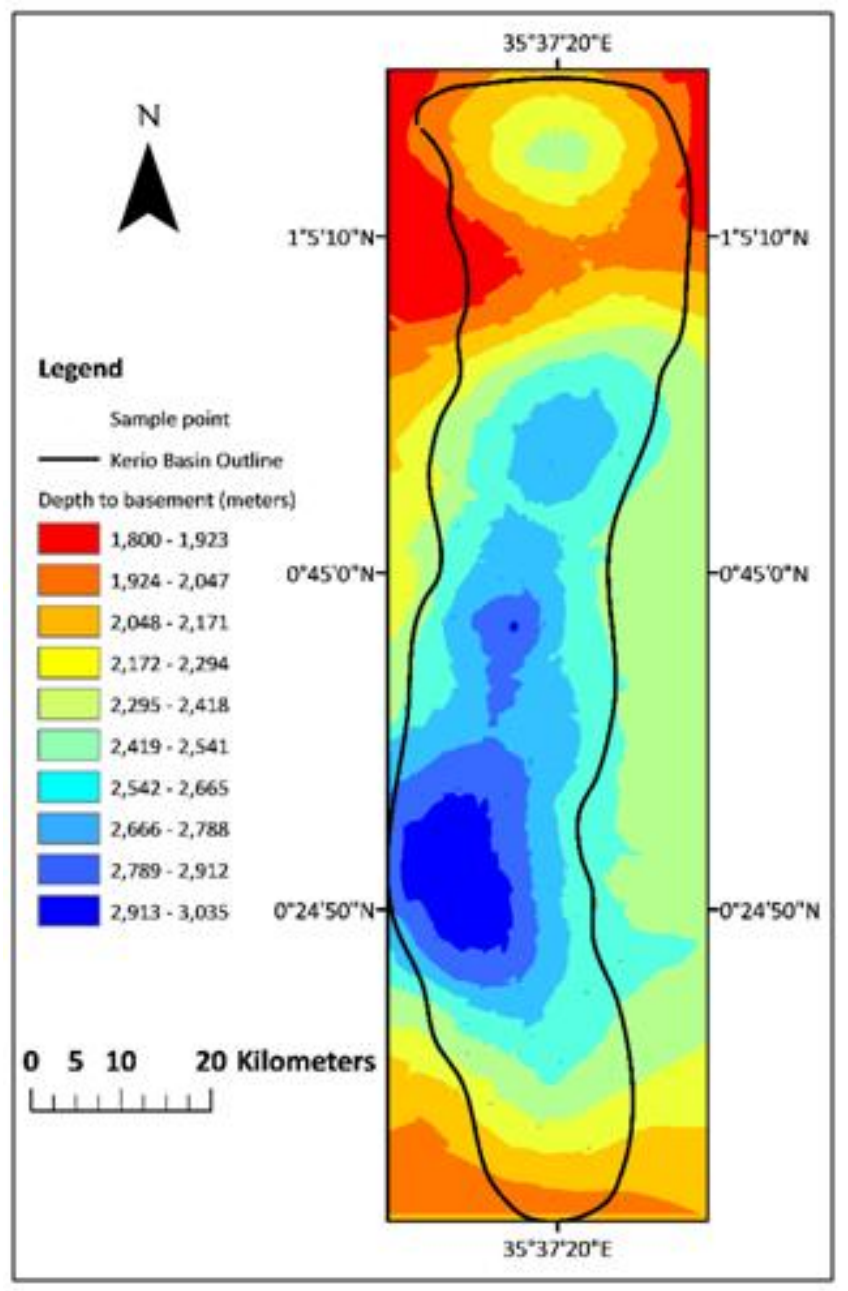

Figure 6:Basement depth estimation map

The south-west section has basement depth range of between $2 \mathrm{~km}$ to $3.5 \mathrm{~km}$ representing the deepest the deepest depression of the basin. This corresponds to both gravity and magnetic interpretation of the same area.

\section{Conclusion}

From the objectives set, the study reveals a dominant gravity anomaly trending north-south, related to the major rift axis. Sedimentation is constrained by the two major normal faults on either side of the basin. Sediment thickness increases southwards showing that the basement rocks are far deeper in the southern region of the study area. This is confirmed by magnetic data that reveals sediment thickness of more than $3 \mathrm{~km}$ in the southern region of the basin. An integrated geophysical approach that incorporates a local seismic and/or exploratory well in the identified prospect south of the basin is recommended to verify the preliminary studies.

\section{References}

[1]. Peytchev, P., et al. Significance of Well Construction; Operational Efficiency in Remote Areas-Tullow Kenya's Remarkable Cost Reduction Journey. in SPE/IADC Middle East Drilling Technology Conference and Exhibition. 2016. Society of Petroleum Engineers.

[2]. Hubert, D., The Use of Tax Havens in the Ownership of Kenyan Petroleum Rights. 2016.

[3]. Roy, A., Ambiguity in geophysical interpretation. Geophysics, 1962. 27(1): p. 90-99.

[4]. Bonvalot, S., et al., World Gravity Map., Bureau Gravimetrique International (BGI), map, 2012, CGMW-BGI-CNES-IRD Ed., Paris. 
[5]. Andersen, O.B. The DTU10 Global Gravity field and mean sea surface-improvements in the Arctic. in 2nd IGFS meeting. 2010.

[6]. Maus, S., et al., EMAG2: A 2-arc min resolution Earth Magnetic Anomaly Grid compiled from satellite, airborne, and marine magnetic measurements. Geochemistry, Geophysics, Geosystems, 2009. 10(8).

[7]. Tullow, Tullow Oil plc-2015 Half Year results. 2015.

[8]. AfricaOil, Fourth Quarter and Full Year Financial and Operating Results. 2014.

[9]. Mariita, N.O. and G.R. Keller, An integrated geophysical study of the northern Kenya rift. Journal of African Earth Sciences, 2007. 48(2): p. 80-94.

[10]. Simiyu, S.M. and G.R. Keller, An integrated geophysical analysis of the upper crust of the southern Kenya rift. Geophysical Journal International, 2001. 147(3): p. 543-561.

[11]. Simiyu, S.M. and G.R. Keller, An integrated analysis of lithospheric structure across the East African plateau based on gravity anomalies and recent seismic studies. Tectonophysics, 1997. 278(1): p. 291-313.

[12]. Swain, C., P. Maguire, and M.A. Khan, Geophysical experiments and models of the Kenya Rift before 1989. Tectonophysics, 1994. 236(1): p. 23-32.

[13]. Swain, C., The Kenya rift axial gravity high: a re-interpretation. Tectonophysics, 1992. 204(1): p. 59-70.

[14]. Swain, C., et al., Seismic and gravity surveys in the Lake Baringo-Tugen Hills area, Kenya rift valley. Journal of the Geological Society, 1981. 138(1): p. 93-101.

[15]. Fairhead, J., The structure of the lithosphere beneath the Eastern Rift, East Africa, deduced from gravity studies. Tectonophysics, 1976. 30(3): p. 269-298.

[16]. Morley, C., et al., AAPG Studies in Geology\# 44, Chapter 2: Geology and Geophysics of the Western Turkana Basins, Kenya. 1999.

[17]. Morley, C., AAPG Studies in Geology\# 44, Chapter 8: Basin Evolution Trends in East Africa. 1999.

[18]. Mugisha, F., et al., Two-stage rifting in the Kenya rift: implications for half-graben models. Tectonophysics, 1997. $278(1)$ : p. 63-81.

[19]. Le Gall, B., W. Vétel, and C. Morley, Inversion tectonics during continental rifting: The Turkana Cenozoic rifted zone, northern Kenya. Tectonics, 2005. 24(2).

[20]. Macgregor, D., History of the development of the East African Rift System: A series of interpreted maps through time. Journal of African Earth Sciences, 2015. 101: p. 232-252.

[21]. Hautot, S., et al., Deep structure of the Baringo Rift Basin (central Kenya) from three-dimensional magnetotelluric imaging: Implications for rift evolution. Journal of Geophysical Research: Solid Earth, 2000. 105(B10): p. 23493-23518.

[22]. Hendrie, D., et al., Cenozoic extension in northern Kenya: a quantitative model of rift basin development in the Turkana region. Tectonophysics, 1994. 236(1-4): p. 409-438.

[23]. Odada, E.O. and D.O. Olago, The East African Great Lakes: Limnology, Palaeolimnology and Biodiversity. Vol. 12. 2006: Springer Science \& Business Media.

[24]. Renaut, R., et al., Saline, alkaline palaeolakes of the Tugen Hills-Kerio Valley region, Kenya Rift Valley. Late Cenozoic Environments and Hominid Evolution: A Tribute to Bill Bishop. Geological Society, London, 1999: p. 41-58.

[25]. Chapman, G.R. and M. Brook, Chronostratigraphy of the Baringo basin, Kenya. Geological Society, London, Special Publications, 1978. 6(1): p. 207-223.

[26]. Verduzco, B., et al., New insights into magnetic derivatives for structural mapping. The Leading Edge, 2004. 23(2): p. 116-119.

[27]. Kucks, R.P., Isostatic residual gravity anomaly data grid for the conterminous US. 1999.

[28]. Fairhead, J.D., et al., New developments of the magnetic tilt-depth method to improve structural mapping of sedimentary basins. Geophysical Prospecting, 2011. 59(6): p. 1072-1086.

[29]. Salem, A., et al., Tilt-depth method: A simple depth estimation method using first-order magnetic derivatives. The Leading Edge, 2007. 26(12): p. 1502-1505.

[30]. Fairhead, J.D., A. Salem, and S.E. Williams, PS Tilt-Depth: A Simple Depth-Estimation Method Using First Order Magnetic Derivatives*. 2009.

[31]. Purucker, M.E. and D.A. Clark, Interpretation of the lithospheric magnetic field. Geophys. J. Int.,(in Press), 2010.

[32]. Tiercelin, J.-J., et al., Hydrocarbon Prospectivity in Mesozoic and Early Cenozoic Rift Basins in Central/Northern Kenya. Search and Discovery, Article, 2009. 10188.

[33]. Pedersen, L. and T. Rasmussen, The gradient tensor of potential field anomalies: Some implications on data collection and data processing of maps. Geophysics, 1990. 55(12): p. 1558-1566. 